\title{
A Qualitative Study on the Sustainability of Single-Parent Students in Ningxia Polytechnic
}

\author{
Jiang Yaqiong 1,a, Arasinah Kamis ${ }^{2, b}$, Ridzwan Bin Che`'Rus ${ }^{3, c}$ \\ ${ }^{1}$ Ningxia Polytechnic, Yinchuan, Ningxia, China \\ ${ }^{2}$ Sultan Idris Education University, Tanjung Malim, Perak, Malaysia \\ ${ }^{3}$ Sultan Idris Education University, Tanjung Malim, Perak, Malaysia \\ a765740243@qq.com, barasinah@ftv.upsi.edu.my, cridzwan@ftv.upsi.edu.my
}

Keywords: Single-Parent Students, Sustainable development, Qualitative research

\begin{abstract}
Exploring the current status of sustainable development ability of single-parent families in Ningxia Polytechnic, and proposing corresponding educational countermeasures and methods. Taking the purposeful sampling method, $10 \mathrm{key}$ personnel including counselors, professional teachers, and 15 single-parent students were selected for personal in-depth interviews, and the teaching process of 3 professional training courses was observed. Most students showed poor sustainability and differences in the sustainability of individual single-parent families. Exploring the effective ways and means of school for sustainable development education for single-parent families has become an important task for every educator.
\end{abstract}

\section{Introduction}

With the continuous development of market economy, people's marriage concept is changing step by step. The number of abnormal families, ike single parent families, divorced families, and other situations is increasing by years. The number of people who go through the formalities of divorcing in 2016 is 4.158 million couples, an increase of $8.3 \%$ over the previous years. The rate of divorce is $3.0 \%$, an increase of $0.2 \%$ over the previous years. The decade from $2007-2016$, the number of people who get a divorce in China is added up to 30.62 .8 million couples, and the growth rate is added up to $98.1 \%$.The date is driving from (ChinaThe State Council, 2017). With the rapid increase in the divorce rate in China, the number of groups in the group has also increased accordingly, that is, the minor children of single-parent families. Single-parent families are more likely to expose their children to serious physical trauma. They are socially disadvantaged groups, incomplete family structure, lack of fatherly love or maternal love, and the problems of children's psychology, education, behavior, etc. caused by single parents are endless, and need to attract common attention from families, schools and society.

The study on the issue of the vocational college education is carried out from multiple views, while the research on problem behavior of vocational colleges has always been the focus of the education sector, but a series of problem behaviors of single- Parents students are even the most important things in education. Although researchers have different views on the connotation of ongoing education in training and training, most scholars also have some consensus. only a lack of more comprehensive and in-depth research. This article will comprehensively study the sustainable development of single-parent family education in vocational schools. From the perspective of student management, it solves a gap in Ningxia Polytechnic's management of single-parent families in the study of students' sustainable development. Incorporate the intrinsic value of sustainable into the learning aspect to en Courage change in the behavior of problem students to achieve a more sustainable and just society and contribute to social construction.

To explore the sustainability of education and training for vocational college students in the context of single-parent families, the focus of this paper is to discuss aspects of case study research, qualitative data the theory and arguments affecting the choice of research and data gathering strategy in this research. 


\section{Research objects and methods}

\subsection{Research objects}

After studying the problem entirely exploratory study nature in clear cases, researchers need to interview the selected object, which is the basis for the design of interview questions. This study interviews the results of a joint effort of teachers, students, and student managers. This study selected students (15), teachers (5), student managers (5), using purposeful sampling procedures. The selection process is often used for qualitative education research ${ }^{[1]}$.

\subsection{Methods}

The interview method is mainly aimed at the problems related to the sustainable development of vocational students in Vocational schools, and interviews teachers and single-parent families to obtain qualitative conclusions. In the process of identifying the research objects, researchers started the process of data collection, mainly using in-depth interviews In which observation and informal conversation were the methods of data collection. During the interview, Researcher also suggested that what the interviewee feels can be recorded through his own habits such as writing a diary, a weblog, and writing microblogs.

This is an important qualitative research method in this study. Through in-depth interviews with literature review and special cases, the subjective ideas in the study of single-parent families are explored, which is of great reference to the reasons behind the phenomenon of single-parent family students. value. At the same time, this study also conducted semi-structured interviews with instructors and counselors, in order to obtain teacher-level perspectives from outside the student level and to carry out various problems arising from learners in the sustainable teaching mode of vocational education. All aspects, multi-angle analysis, and exploration. In addition, the dialogue with teachers can not only reveal the reasons for student performance from another perspective of the classroom but also give some advantages and disadvantages of teaching methods. In both types of interviews with teachers and students, 8-10 questions related to the survey results were developed to ensure that the discussion on the reasons behind the sustainability of education and training for single-parent families is more in-depth and Targeted.

\subsection{Statistical Analysis}

Record the recorded data and pen into the database, and then use the subject frame analysis method to combine the qualitative interview outline and the new problems in the interview data to form the subject frame, then conduct qualitative analysis, phenomenon description and problem disclosure, and Reasonable inferences are made about the underlying causes of these problems.

\section{Problem}

Through the information obtained in the interviews, the problems of the divorced single-parent students in the sustainable development of vocational education are summarized:

\subsection{Family aspect}

In single-parent families, a large number of single-parent families often face greater economic pressure. In interviews, parents of single-parent families have expressed some concern about the funding of their children. Parents hope to improve their financial ability so that They can support their children to continue their studies. They have to work harder to give their children a better educational environment. due to financial problems, this not only caused the school to lose its students, but also caused the loss of talent and The pursuit of the student's own life value ${ }^{[2]}$.

Some parents also have poor comprehensive quality and educational ability, and poor education methods lead to some children's bad behavior ${ }^{[3]}$. 


\subsection{Student personal problem}

Students have many personal problems that are analyzed through the results of classes and interviews. Because of the broken family, their hearts have been dealt a heavy blow, which has also hindered their psychological development. This shows that vocational school students need to have knowledge of psychology and mental health, because students at this stage are the turning point in the formation of outlook on life. Self-control is weaker than that of ordinary colleges and universities, and requires timely psychological counseling.

\subsection{School aspect}

The school does not pay enough attention to the development of sustainable development ability of single-parent families. Higher vocational education only pays attention to the development of all students in the school, but ignores the comprehensive and sustainable development of single-parent students $^{[4]}$. It has caused too much emphasis on skills training in the process of talent cultivation, neglecting humanistic quality, and not paying attention to the cultivation of students' sustainable development ability. Higher vocational colleges do not have courses related to the development of sustainable development ability. They do not pay enough attention to the professional quality and sustainable development ability of higher vocational students, and ignore the long-term development of higher vocational students.

\section{Countermeasures}

"For the comprehensive and sustainable development of people" should be the most important concept of vocational education. To establish such a concept, we should start from school,family, personal and other aspects to work together.

\subsection{Home school co-education}

Student education is not only a matter of school, but also a matter of family. It is necessary to adopt an effective method and coordinate the actual situation of the students to achieve good results. The school must be a single-parent family student long creates conditions, often cares about the performance of single-parent families and provides them with the necessary help. According to the individual characteristics of students, help students set a goal, let students have the direction and motivation of development, enable students to develop Self-learning "self-management" self-improvement awareness, and promote the cultivation of students' sustainable development.

\subsection{Strengthen psychological education}

According to the specific situation of single-parent families, choose the main contact person of the family, so that they can not only understand the performance of the students at home, but also guide the parents to continuous improve the level of family education, let They know the learning and living conditions of their children at school.carry out various forms of activities, weaken negative behaviors, and enhance the self-confidence of single-parent families. Integrate mental health education and physical fitness exercises into sports skills learning. Must also shoulder the responsibility of educating people and work hard for the Long-term development of students.

\subsection{The school grasps the direction of vocational education and changes the educational concept}

Higher education should change their ideas, not only focus on training students' professional ability, but also the ability to focus on training students for sustainable development

Higher vocational education must first be people-oriented, adhere to both technical education and humanities education, do things education and human education simultaneously, achieve the all-round development of talent quality, and shape high-level professional and technical personnel that meet the needs of social and economic development and sustainable development. A new concept of running a school should be established, a school-running philosophy that is in line with the development of modern vocational education, and a school-running philosophy that enables the 
sustainable development of higher vocational colleges to guide our school-running activities. Pay attention to the students' experience in learning, follow the cumulative and procedural laws of learning, adopt various evaluation methods, focus on improving students' comprehensive development ability and skills practice ability, focus on ability training, and construct learning students apply practical knowledge and technology to solve practical capabilities in production, service, and management.

\section{Summary}

This study investigated the ability of single-parent families to improve sustainability through vocational education and training at Ningxia Vocational and Technical College. The study used the theory of sustainable development in vocational education as the basis for this theory. The study aimed to explore the sustainable development of single-parent students can be drawn that contribute to the sustainable development of vocational school students ${ }^{[6]}$.

Education for development should run through all aspects of school education and teaching and all aspects of students' social life. Education for development is based on the development of after sustainable development values. It is focused on the development of people of people. The concept of The content of the overall education mode of social sustainable development. The analysis shows that the popularity of culture sustainable culture is relatively optimistic but there are still some omissions. Results show that different living environments have concepts for sustainable development. The formation of the role has played a certain role, different disciplines are not the same for sustainable development.

This paper discusses the problem of single-parent students in vocational colleges and makes theoretical analysis.Having the following characteristics: 1 In terms of methodology, qualitative research is used to understand the single-parent students of Ningxia Polytechnic. Qualitative research focuses on the process of causing results by reason, and the Exploration of unknown areas can provide more information ${ }^{[7]}$. In addition, the results of qualitative research can also provide clues for subsequent quantitative research. 2 By understanding the current status of students' studies sustainable development, For higher vocational education, it is necessary to improve of training technical and vocational students ability and better adapt to future work and study. it puts forward recommendations for Further education for sustainable development, and points out the direction for future student development and opens up new horizons.

\section{References}

[1] Cohen.Manion.Morrison. (2000). Research Methods in Education (5th Edition). London: Routledge Falmer.

[2] Wang Xiaomei. (2008). Thinking about education problems of single parent families in vocational schools. Liaoning Educational Administration Institute.

[3] Wu Jizhong. (2012). a study on the education of single parent families in vocational colleges. Education: Higher Education Research, 57-58.

[4] Zhu Yongxin. (2012). Vocational education: for the comprehensive sustainable development of people. Vocational and technical education, 5-8.

[5] Li Yujing. (2015). Vocational Education Development under the 2030 Agenda for Sustainable Development. Vocational and Technical Education.

[6] Yang Kexin. (2005). Study on the sustainable development of students in vocational schools. Vocational Education BBS, 91, 399-404.

[7] Feng Xiaotian. (2018). Differences between qualitative research and quantitative research and their combination. Journal of Jiangsu Administration Institute, 68-74. 